\title{
The 2012 US Presidential Election Polls
}

\section{And Stock Returns}

\author{
Tamir Levy \\ Netanya Academic College, Israel \\ E-mail: levitami@ netanya.ac.il \\ Joseph Yagil \\ Haifa University and Carmel Academic College, Israel \\ E-mail: yagil@gsb.haifa.ac.il
}

Received: June 3, 2015 Accepted: June 27, 2015

doi:10.5296/ber.v5i2.8005 URL: http://dx.doi.org/10.5296/ber.v5i2.8005

\begin{abstract}
This study investigates the relationship between daily US presidential election poll results and stock returns. The sample consists of the daily presidential election polls published in the New-York Times for the period between May 31 and November 5, 2012. They include the percentage of support for the Democratic candidate, Barack Obama, and the Republican candidate, Mitt Romney. The findings indicate that stock returns are positively related to the poll results that support the candidate favored to win the election.
\end{abstract}

Keywords: Stock Returns, Election Polls.

\section{Introduction}

Scholars have studied stock market performance before, during, and after US presidential election years (e.g., Hirsch, 1967; Jeffery and Hirsch, 2005), and the predictive ability of election polls (e.g., Gemmill, 1992; Gwilym and Buckle, 1994). Similarly, Levy and Yagil (2012) examined the relationship between daily US presidential election poll results and stock returns for the 2008 election, and found that stock returns are positively related to the poll results that support the candidate favored to win the election (Barack Obama).

In this study we investigate whether the relationship between poll results and the predicted 
winning candidate found by Levy and Yagil (2012) for the US 2008 presidential elections also holds for the 2012 elections. In other words, does an increase in the daily percentage of support for the candidate predicted to win the election generates a positive market reaction?

Using a sample of 159 daily polls published in The New York Times between May 31 and November 5, 2012, we find a statistically significant positive relationship between the poll results in favor of the favorite presidential candidate (Obama) and the daily change in the S\&P 500 Index. This positive relationship reflects an increase in the partial resolution of the uncertainty about who the winning candidate will be.

The organization of this study is as follows. Section 1 presents a brief scientific background. Section 2 outlines the methodology and the sample. Section 3 discusses the findings. Section 4 summarizes the results, and the last section concludes the paper.

\section{Scientific Background}

\subsection{Elections and Stock Returns}

Numerous scholars have investigated the relationship between American presidential elections and the stock market. According to Hirsch's (1967) election cycle theory, US stock markets make larger gains in the last two years of the presidential term than in the first two years, in part because wars, recessions and bear markets tend to start or occur in the first half of the presidential term (See, e.g., Foerster and Schmitz, 1997; Hirsch, 1967; Jeffery and Hirsch, 2005). Other studies focus on the stock market's performance relative to a particular political party. They document that stock markets perform better under Democratic presidents than Republican presidents (Chittenden et al., 1999; Hensel and Ziemba, 1995; Santa-Clara Valkanov, 2003; Sigel, 1998).

Over the last 60 years, stock returns in the US have been higher during the last two years of a presidential administration than during the first two (Hofschire, 2008). More specifically, the annual mean return on the S\&P 500 Index over that period has been $7.6 \%, 9.8 \%, 22.3 \%$ and $13.1 \%$ for the first, second, third and fourth years of a presidential administration, respectively. Furthermore, the differences between these rates are statistically significant. In contradiction to the common perception that the Republican Party is more business oriented, the mean return over the past six decades during Republican administrations has been $11.4 \%$ per annum compared with a corresponding return of $16.0 \%$ for Democratic administrations. More specifically, stock returns during Democratic years have been higher than those during Republican years for the first, third and fourth years of a presidential administration. Once again, these differences are statistically significant.

Oehler, Walker and Wendt (2013) document that the elections of all recent U.S. presidents, regardless of their political affiliation, have prompted abnormal company and sector returns. Goodell and Vahamaa (2013) have used monthly Iowa Electronic Markets data over five elections, and documented that stock market uncertainty, as measured by the VIX volatility index, increases along with positive changes in the probability of success of the eventual winner. 
Studies dealing with the question of how election polls affect stock markets include that of Levy and Yagil (2012), Gemmill (1992), Gwilym and Buckle (1994) and Brander (1991). As noted above, Levy and Yagil (2012), examined the relationship between daily US presidential election poll results and stock returns for the 2008 election, and found that stock returns are positively related to the poll results that support the candidate favored to win the election (Barack Obama).

Gemmill (1992) who examines the behavior of the stock and options markets in London during the 1987 election. He finds an extremely close relationship between opinion polls and the share prices of the FTSE 100 Index. Gwilym and Buckle (1994) extend Gemmill's study to the 1992 election. They also find a close relationship between the opinion polls and the FTSE 100 Index, but determine that the prices of the FTSE 100 Index options do not follow the polls as closely.

Similarly, Brander (1991) examines the effect of public opinion polls on the Toronto Stock Exchange (TSE) during the campaign period of the 1988 Canadian general election, discovering a positive relationship between the TSE and the popularity of the Conservative Party in the polls.

\subsection{The 2012 US Presidential Elections}

Given this preliminary literature, we investigate whether daily changes in the polls affect market returns. In addition, is there a potentially positive relationship between poll results that favor the Democratic candidate and stock market reactions?

Several factors lead us to make such a prediction. The first factor stems from the results of Levy and Yagil (2012), who found a positive relation between the stock returns and polls results that favor the Democratic candidate (Barack Obama). Second, in recent years there has been a strong link between the welfare and pensions of Americans. Therefore, dismal market returns may improve the chances of the candidate promising a change, in this case, Democrat Barack Obama. Third, the fact that historically, stock returns during Democratic years have been higher than those during Republican years may contribute to a positive relationship between support for the Democratic candidate in the polls and stock returns.

Based on these arguments, we hypothesize that an increase in the poll results in favor of the Democratic candidate during the 2012 US presidential race will have a positive relationship with stock returns. Another point to note is that when the polls indicate a close 50-50 race, market reaction can be negative. The positive reaction of certain market participants to the better poll results for their favorite candidate may be offset by the negative reaction of other participants to the same results. In contrast, when the polls indicates a clear public preference, the emergence of stronger poll support for the favorite candidate will likely lead to a (net) positive market reaction.

\section{Methodology and Data}

\subsection{Methodology}

To investigate the relationship between poll support for a certain candidate and stock returns, 


\section{Al Macrothink}

we estimate the following regression equations:

$$
\begin{aligned}
& R_{t}=b_{0}+b_{1} C_{1, t}+e_{t} \\
& R_{t}=b_{0}+b_{1} C_{2, t}+e_{t}
\end{aligned}
$$

where $R_{t}$ is Period t's rate of return for a stock index, $C_{1, t}$ and $C_{2, t}$ are the change in the level of support for Candidates 1 and 2, respectively, e is the error term, and $b_{0}$ and $b_{1}$ are the OLS coefficients. Given the expected high negative correlation between $C_{1}$ and $C_{2}$, we do not include these two variables in the same regression equation to avoid the problem of multicollinearity. The discussion in the prior section implies that, if candidate 1 is the favorite, we should expect $b_{1}$ to be positive for $C_{1}$ in Eq. (1) and negative for $C_{2}$ in Eq. (2), or, alternatively, that the statistical significance level associated with $C_{1}$ will be higher than that associated with $C_{2}$; i.e., $\alpha_{1}<\alpha_{2}$, where $\alpha$ represents the statistical significance level.

Following Levy and Yagil (2012b), we add two dummy variables to the regression. The first variable is for days which are in Week 43 of the year (between October 21 and October 28) $\left(W_{43}\right)$, while the second is for days which are in Week 44 (between October 29 and November 4) $\left(W_{44}\right)$.

To check for the day-of-the-week effect, we incorporate another dummy variable $\left(M_{t}\right)$ into Eq. (1), whose values are 1 for Mondays and 0 otherwise. Finally, to detect a potential time serial correlation, we also include the previous day's return $\left(R_{t-1}\right)$ as another explanatory variable. Consequently, the extended version of Eq. (1) becomes

$$
R_{t}=a+b_{1} C_{1, t}+b_{2} W_{43, t}+b_{3} W_{44, t}+b_{4} M_{t}+b_{5} R_{t-1}+e_{t}
$$

where all notations are as defined above. A zero's of $b_{2}, b_{3}$ and $b_{4}$ implies no Week-of-the-Year effect $\left(b_{2}, b_{3}\right)$ and no Monday effect $\left(b_{4}\right)$, and a zero $b_{5}$ indicates no time serial correlation of returns. 


\subsection{Data and Measurement of the Variables}

Our presidential election poll sample consists of all daily polls published in The New York Times between May 31 and November 5, 2012. The poll results were taken from http://fivethirtyeight.blogs.nytimes.com/, and it included two daily values: the percentages of support for the Democratic candidate, Barack Obama, and the Republican candidate, Mitt Romney.

The variable $C_{1, t}\left(C_{2, t}\right)$ represents the change in the level of support for the Democratic (Republican) candidate between Days $t$ and $\mathrm{t}-1$. We measure the stock return $\left(R_{t}\right)$ as the daily change in the closing level of the S\&P 500 Index between Day t and t-1. In addition, we use two other measures for $R_{t}:$ (1) the daily change between the opening price of the S\&P 500 Index on Day $\mathrm{t}$ and the closing price on Day $\mathrm{t}-1$, and (2) the daily change between the opening price and the closing price of the stock index on Day $t$.

\section{Results}

Figure 1 represents the daily poll results for the Democratic and Republican candidates.

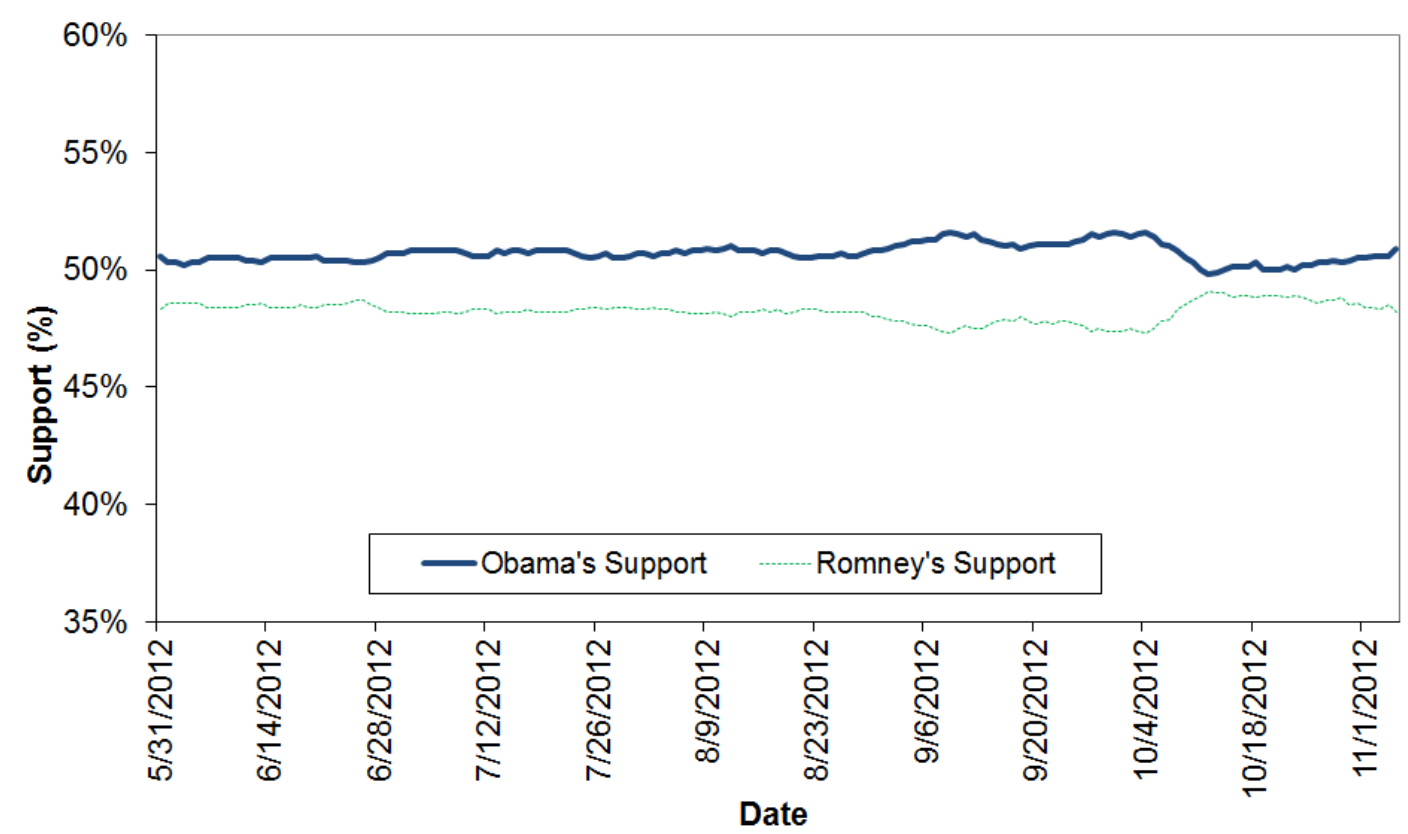

Figure 1. Support for Obama and Romney between May 31, 2012 and November 05, 2012.

The Figure describes the support in Obama and in Romney.

Figure 2 presents the S\&P 500 Index for the period between May 31 and November 5, 2012. 


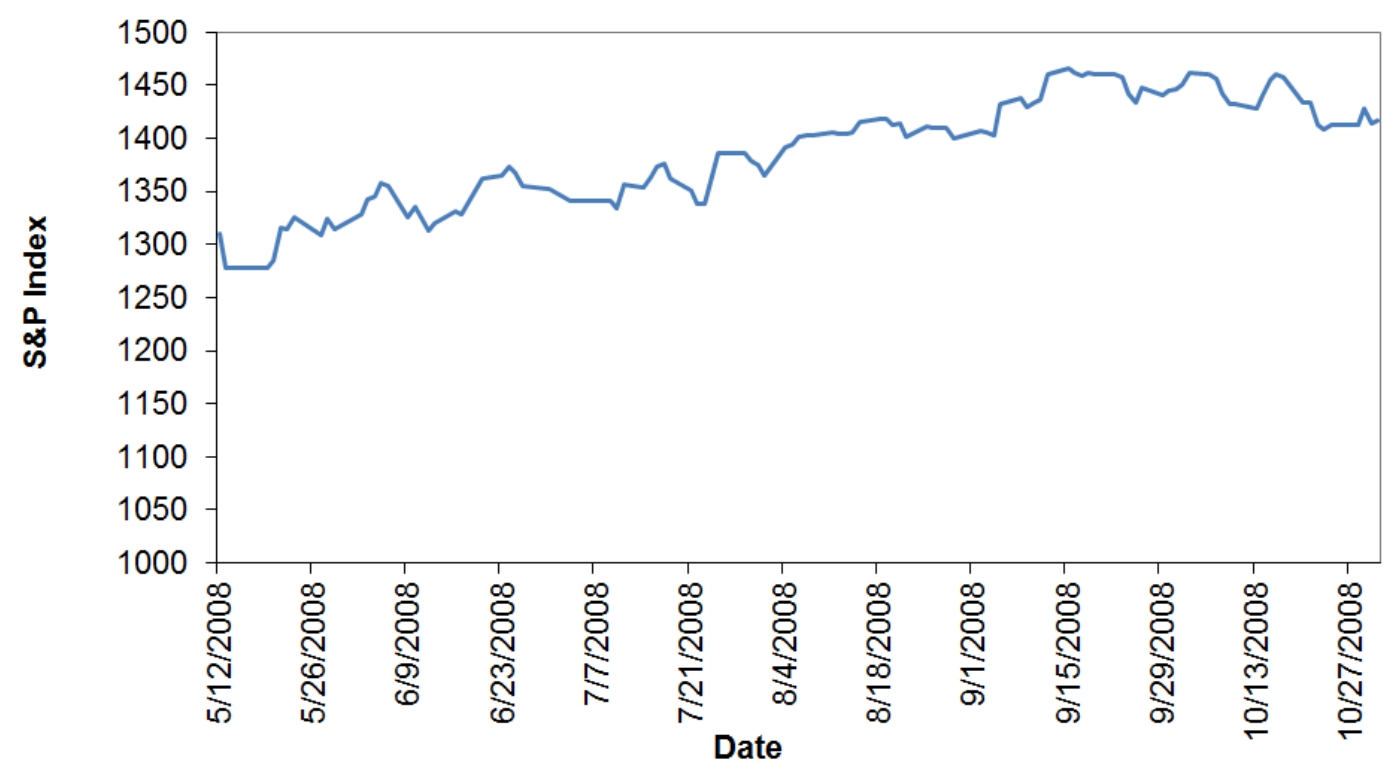

Figure 2. The S\&P 500 Index For the Period between May 31, 2012 and November 05, 2012.

The main hypothesis test results - that an increase in the poll results in favor of the Democratic candidate is positively related to stock returns - are represented by the estimation result of Eq. (3) given below:

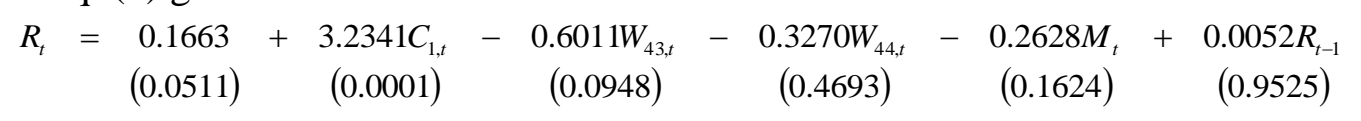

$R^{2}=0.2394 ; n=109 \quad ; \quad \alpha=0.0001$

where the numbers in parenthesis are the significance level. For the less favorable presidential candidate, Mitt Romney, the corresponding results are as follows:

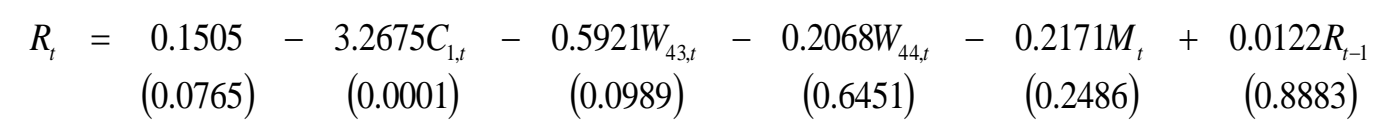

$R^{2}=0.2425 \quad ; \quad n=109 \quad ; \quad \alpha=0.0001$

The findings demonstrate that our hypothesis regarding the positive relationship between poll results that favor the Democratic candidate and stock market reactions exists.

The findings in Eqs. (4) and (5) indicate that the Week-of-the-Year effect regarding Week 43 exists with statistically significant coefficients. The findings in Eqs. (4) and (5) also indicate that the Monday effect is negative but not statistically significant, and that no time serial correlation is present. These results imply that, as we hypothesize, stock returns are positively related to poll results that support the favorite candidate, perhaps due to the reasons we outline in Section 2.

In addition, to investigate whether the time distance from Election Day affects the 
relationship between poll results and stock returns, we divide the polls' total sample period into three equal sub-periods: (1) closest to Election Day, (2) farthest away from Election Day and (3) equidistant to Election Day. Accordingly, we estimate a similar version of Eq. (1):

$$
R_{t}=b_{1} D_{t}^{\text {Close }}+b_{2} D_{t}^{\text {Middle }}+b_{3} D_{t}^{\text {Far }}+b_{4} D_{t}^{\text {Close }} C_{1, t}^{\text {Close }}+b_{5} D_{t}^{\text {Middle }} C_{1, t}^{\text {Middle }}+b_{6} D_{t}^{\text {Far }} C_{1, t}^{\text {Far }}+e_{t}
$$

We have divided the sample into three equal groups, and used three dummy variables $D_{t}^{\text {Close }}, D_{t}^{\text {Middle }}$ and $D_{t}^{\text {Far }}$. The first,$D_{t}^{\text {Close }}$, equals to 1 for the period nearest to Election Day, and 0 otherwise. Similarly, $D_{t}^{F a r}$, is a dummy variable, which equals to 1 for days farthest away from Election Day, and 0 otherwise. The $D_{t}^{\text {Middle }}$ represent the dummy variable for the intermediate group.

The estimation results are as follows:
$R_{t}=0.0463 D_{t}^{\text {Close }}$
(0.6897) $0.1669 D_{t}^{\text {Middle }}$
(0.1512) $0.0211 D_{t}^{F a r}$
$(0.8557)$ $+7.8426 D_{t}^{\text {Close }} C_{1, t}^{\text {Close }}+$
$(0.0001)$ $2.6441 D_{t}^{\text {Middle }} C_{1, t}^{\text {Middle }}+1.0153 D_{t}^{\text {Far }} C_{1, t}^{\text {Far }}$

$$
R^{2}=0.3813 \quad ; n=108 \quad ; \quad \alpha=0.0001
$$

Since our sample includes 109 trading days, we have deleted the first observation (May 31). The other 108 observations were divided into 3 equal groups of 36 observation each.

These findings indicate that the positive relationship between stock returns and support of the favorite candidate in the polls occurs mainly in the time period closest to Election Day.

Our findings are different than those of Levy and Yagil (2012), who found that the positive relationship, between stock returns and the support granted to the favorite candidate in the polls, occurs mainly in the time period closest to Election Day.

\section{Conclusions}

This study examines the relationship between daily US presidential election poll results and stock returns. Specifically, it investigates whether an increase in the daily percentage of support for the favorite candidate generates a positive market reaction.

Our sample consists of all daily presidential election polls published in The New York Times between May 31 and November 5, 2012. The poll results include the percentage of support for the Democratic candidate, Barack Obama and the Republican candidate, Mitt Romney.

The regression results imply that stock returns are positively related to the poll results that support the favorite Democratic candidate. We also find that support in the polls for the favorite candidate occurs mainly in the period farthest to Election Day. This finding probably 
reflects an increase in the partial resolution of the uncertainty about who the winning candidate will be.

\section{References}

Lawrence, S. et al. (2001). Persistence of Web References in Scientific Research. Computer, 34, 26-31. http://dx.doi.org/10.1109/2.901164

Smith, Joe. (1999). One of Volvo's core values. [Online] Available: http://www.volvo.com/environment/index.htm (July 7, 2007)

Strunk, W., Jr., \& White, E. B. (1979). The elements of style (3rd ed.). New York: Macmillan, (Chapter 4).

Van der Geer, J., Hanraads, J. A. J., \& Lupton R. A. (2000). The art of writing a scientific

Brander, J.A.. (1991). Election Polls, Free Trade, and the Stock Market: Evidence from the 1988 Canadian General Election, Canadian Journal of Economics, 24(4), 827-43. Copyright Disclaimer

Copyright for this article is retained by the author(s), with first publication rights granted to the journal.

This is an open-access article distributed under the terms and conditions of the Creative Commons Attribution license (http://creativecommons.org/licenses/by/3.0/).

Chittenden, W., Gerald R. Jensen, \& Robert R. Johnson. (1999). Presidential Politics, Stocks, Bonds, Bills, and Inflation, Journal of Portfolio Management Fall, 63- 79.

Foerster, S. R., \& J. J., Schmitz. (1997). The Transmission of US Election Cycles to International Stock Returns. Journal of International Business Studies, 28, 1-27. http://dx.doi.org/10.1057/palgrave.jibs.8490089

Gemmill, G. (1992). Political Risk and Market Efficiency: Tests Based in British Stock and Options Markets in the 1987 election. Journal of Banking and Finance, 16(1), 211-231. http://dx.doi.org/10.1016/0378-4266(92)90086-F

Goodell, J. W., Vahamaa, S. (2013). US Presidential Elections and Implied Volatility: The Role of Political Uncertainty. Journal of Banking and Finance, 37, 1108-1117. http://dx.doi.org/10.1016/0378-4266(92)90086-F

Gwilym, O. A., \& M., Buckle. (1994). The Efficiency of Stock and Options Market: Tests Based on 1992 UK Election Polls. Applied Financial Economics, 4, 345-54. http://dx.doi.org/10.1080/758536472

Hensel, Chris R., \& William T. Ziemba. (1995). United States Investment Returns During Democratic and Republican Administrations., 1928-1993. Financial Analysts Journal, March-April, 61-69. http://dx.doi.org/10.2469/faj.v51.n2.1882

Hirsch, Y. (1967). Stock Trader's Almanac 1966. Wiley. 


\section{Macrothink}

Business and Economic Research ISSN 2162-4860 2015, Vol. 5, No. 2

Hofschire, D. (2002). 2008 Elections: How Will the Stock Market Vote?", Fidelity Management and Research, February, 11, 1-4.

Levy, T., \& Yagil, J. (2012). The 2008 US Presidential Election Polls and Stock Returns, Archives Des Sciences, 65(11), 49-57.

Levy, T., \&Yagil, J. (2012). The Week-of-the-Year Effect: Evidence From Around the Globe,

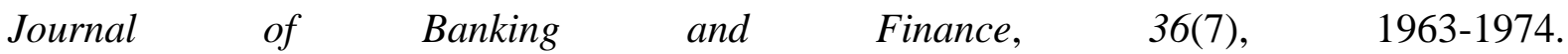
http://dx.doi.org/10.1016/j.jbankfin.2012.03.004

Oehler, A., Walker, J. T., \& Wendt, S. (2013). Effects of Election Results on Stock Price Performance: Evidence from 1980 to 2008. Managerial Finance. 39, 714-736. http://dx.doi.org/10.1108/MF-May-2012-0126

Santa-Clara, P., \& R., Valkanov. (2003). The presidential puzzle: Political cycles and the stock market. Journal of Finance, 58, 1841-1872. http://dx.doi.org/10.1111/1540-6261.00590

Siegel, Jeremy. (1998). Stocks for the Long Run (Norton, New York).

\section{Copyright Disclaimer}

Copyright for this article is retained by the author(s), with first publication rights granted to the journal.

This is an open-access article distributed under the terms and conditions of the Creative Commons Attribution license (http://creativecommons.org/licenses/by/3.0/). 